\title{
Ag Nanoencapsulation for Antimicrobial Applications
}

\author{
Sarah-Luise Abram§, Jacinthe Gagnon, Magdalena Priebe, Nelly Hérault, and Katharina M. Fromm
}

§SCS-DSM Award for best poster presentation in Polymers, Colloids \& Interfaces

\begin{abstract}
Biomaterial-related infections remain a significant challenge in medicine. Antimicrobial materials on the basis of Ag nanoparticles represent a promising solution for this issue. Therefore several $\mathrm{Ag}$-containing nanocontainers and nanorattles have been synthesized and characterized that exhibit remarkable control over the release of $\mathrm{Ag}^{+}$as antimicrobial active species. Their biological evaluation against prokaryotic as well as eukaryotic cells reveals that they fulfill the prerequisites for applications as antimicrobial implant coatings.
\end{abstract}

Keywords: Antimicrobial activity · Implant infections · Nanocontainers · Nanorattles · Silver nanoparticles

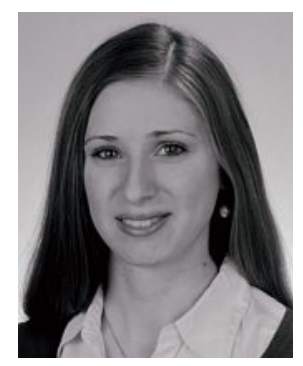

Sarah-Luise Abram studied chemistry at the Humboldt Universität zu Berlin. She obtained her Diploma in 2013 working on the stabilization of reactive $\mathrm{Cu}$-nitrene units for $\mathrm{C}-\mathrm{H}$ bond activation in the group of Dr. Kallol Ray. Currently she is carrying out her PhD research under the supervision of Prof. Katharina M. Fromm at University of Fribourg. Her doctoral work is part of the National Center of Competence in Research (NCCR) Bio-Inspired Materials. Her research activities cover the synthesis of functional nanomaterials and their biological testing in bacterial and cell culture.

\footnotetext{
${ }^{\star}$ Correspondence: Prof. Dr. K. M. Fromm University of Fribourg, Department of Chemistry Chemin du Musée 9, $\mathrm{CH}$-1700 Fribourg E-mail: katharina.fromm@unifr.ch
}

\section{Introduction: Ag as Potential Solution to Implant Infections}

Silver has been used for its beneficial properties for many years, e.g. to preserve drinking water from microbial contamination. Today, the interest in silver as an antimicrobial agent recurs in the context of the increasing resistance of pathogens to the $20^{\text {th }}$ century antibiotics. ${ }^{[1]}$ Multidrugresistant microbes are surprisingly susceptible to $\mathrm{Ag}$ as its antimicrobial action is based on a variety of mechanisms, ${ }^{[2]}$ most of which are related to $\mathrm{Ag}^{+}$ions that interact with amino acids or DNA, inhibiting the respiratory chain or blocking the reproduction. Formation of reactive oxygen species and direct damage of the cell membranes are also under discussion.

Metallic silver releases $\mathrm{Ag}^{+}$ions from the surface in presence of oxygen. This effect can be enhanced by increasing the ratio of surface to bulk atoms, using $\mathrm{Ag}$ nanoparticles (AgNP). AgNP-based antimicrobial coatings should possess thus properties to fight implant related infections as these are often caused by multiresistant bacteria strains. ${ }^{[3]}$ Such coatings must support the 'race for the surface', hence prevent the bacterial attachment to the implant surface while promoting the integration of the device into healthy tissue. ${ }^{[4]}$ If not, adhering bacterial cells will form biofilms that are difficult to eradicate, and the so infected implant needs to be removed and replaced after the infection has cleared. Medical progress and increasing numbers of implant operations will enhance the significance of this problem.

One challenge in the development of silver-based antimicrobial coatings is the control over the $\mathrm{Ag}^{+}$ion release, which should be long-lasting and high enough to maintain a biocidal $\mathrm{Ag}^{+}$level to prevent the development of resistance, but low enough to ensure good biocompatibility without adverse effects. Antimicrobial coatings based on $\mathrm{Ag}^{+}$coordination compounds ${ }^{[5]}$ developed in the Fromm group have shown excellent potential for the short-term treatment of implant associated infections, i.e. for perioperative infections with different staphylococci[6] and in synergistic actions with traditional antibiotics.[7] However, longer-lasting protection against the later possible hematogenous infections remains challenging with these coatings. One way to overcome the issue of fast release kinetics is the use of AgNP where oxidative dissolution is required to fully exhaust their antimicrobial potential. This process depends on the environment $(\mathrm{pH}$, ionic strength, organic groups that interact with $\mathrm{Ag}^{+}$) and might be further controlled by restricting the access to the AgNP surface. This can be achieved by integration of AgNP into biocompatible nanostructures, e.g. nanocontainers (NC) can be loaded or doped with $\mathrm{Ag}^{+}$or $\mathrm{AgNP}$ (e.g. see Fig. 1), porous shells can be grown around AgNP resulting in core-shell particles, or AgNP can be encapsulated inside nanorattles (NR or yolk-shell particles, e.g. see Fig. 4). ${ }^{[8]}$ Encapsulation of NP prevents their aggregation/coalescence and preserves their functionality. NC and NR offer additionally a confined space with controlled environment that is advantageous for applications in catalysis as nanoreactors or in drug delivery by providing space for further active compounds, e.g. in theranostics. ${ }^{[9]}$ The shell material further offers ways for surface functionalization to enable covalent attachment to biomaterials or inclusion of targeting moieties.

The synthesis of hollow nanostructures such as NC and NR can be roughly divided into three approaches for the void creation: 
The first possibility is the use of soft templates such as emulsion droplets, supramolecular micelles, polymeric vesicles or gas bubbles. The second, more widely used way are hard templates, which are first coated with the shell and then removed in a second step by selective dissolution or calcination. These solid materials include polymers, oxides, carbon, metals or ceramics. Besides these two general approaches a third category is proposed for so-called 'self-templating' methods where the material of the 'template' and the shell are either very similar or the same. Surfaceprotected etching, Ostwald ripening, galvanic replacement or the Kirkendall effect are typically assigned to this group. ${ }^{[10]}$ Others allocate these processes to the hard template methods referring to them as special 'sacrificial' template methods. ${ }^{[11]}$ A synthesis pathway could also combine features of several of these categories (e.g. microemulsions and self-templating). ${ }^{[12]}$

In this context, different types of Ag@ porous oxide nanoparticles have been investigated for their potential as antimicrobial implant coatings in correlation with their morphology at the nanoscale by studying their properties in biological environments. This review provides an overview of the Ag nanomaterials developed so far in the Fromm group.

\section{Results and Discussion: Encapsulation of Ag into Hollow Nanospheres}

\section{Polystyrene Template Methods: Ag-Ceria and Ag-Titania Nanocontainers}

The synthetic routes presented in this section belong to the hard template methods and consist of the coating of anionic polystyrene (PS) spheres with the desired shell materials: ceria and titania $(\mathrm{CeO}$ and $\mathrm{TiO}_{2}$ ). PS spheres can be synthesized without difficulty in various diameters and are easily removed by either dissolution in e.g. toluene, ${ }^{[13]} \mathrm{THF},{ }^{[14]}$ xylene containing trimethylamine ${ }^{[15]}$ or chloroform, ${ }^{[16]}$ or by calcination at a minimum temperature of $500{ }^{\circ} \mathrm{C}$. For the synthesis of silver containing hollow ceria $\mathrm{NC}\left(\mathrm{AgNO}_{3}-\mathrm{CeO}_{2}\right.$ and $\mathrm{Ag}-\mathrm{CeO}_{2}$, Figs 1 and 2, A and B) $220 \mathrm{~nm}$ PS spheres were coated with $\mathrm{CeO}_{2}$ by hydrolysis of $\mathrm{Ce}(\mathrm{acac})_{3}$ in a sol-gel process.[17] The PS template was removed by calcination at $600{ }^{\circ} \mathrm{C}$ in order to obtain hollow $\mathrm{CeO}_{2} \mathrm{NC}$ with a diameter of 175-200 nm and with 12-20 nm thick walls. They were soaked in a saturated ethanolic $\mathrm{AgNO}_{3}$ solution, resulting in a loading of $0.77 \mathrm{wt} \%$ silver into the $\mathrm{AgNO}_{3}-\mathrm{CeO}_{2} \mathrm{NC}$ after three washing steps. Short exposure to daylight caused a partial reduction of the incorpo-

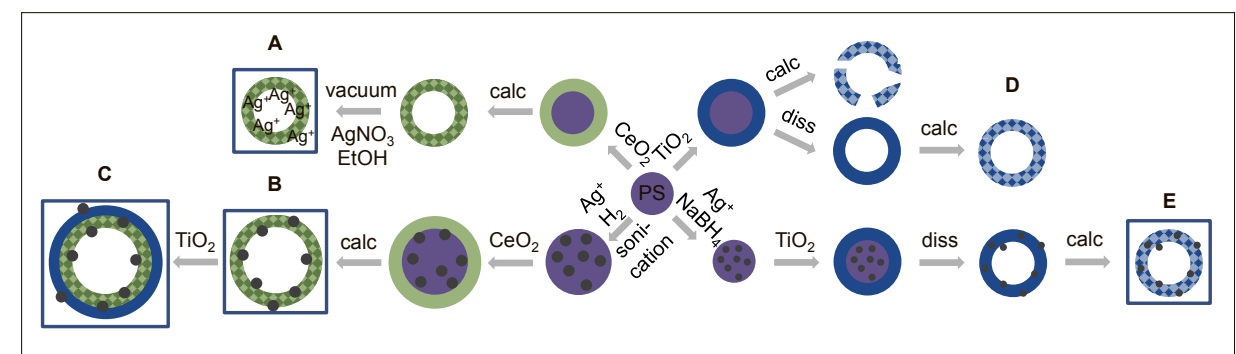

Fig. 1. Synthesis of $\mathrm{AgNO}_{3}-\mathrm{CeO}_{2} \mathrm{NC}(\mathrm{A}), \mathrm{Ag}-\mathrm{CeO}_{2} \mathrm{NC}(\mathrm{B}), \mathrm{Ag}-\mathrm{CeO}_{2} @ \mathrm{TiO}{ }_{2} \mathrm{NC}(\mathrm{C}), \mathrm{TiO}_{2} \mathrm{NC}(\mathrm{D})$, and $\mathrm{Ag}-\mathrm{TiO}_{2} \mathrm{NC}(\mathrm{E})$ from PS template nanospheres. The frames indicate the $\mathrm{NC}$ that were investigated for their antimicrobial properties.

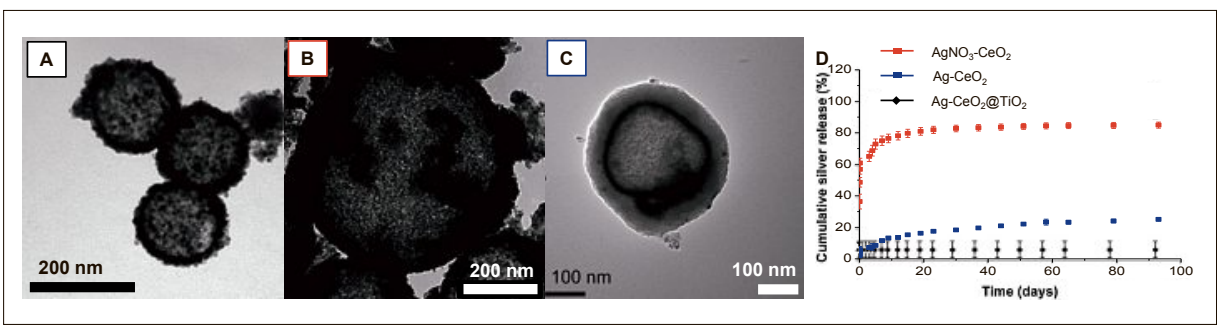

Fig. 2. Transmission electron micrographs of $\mathrm{AgNO}_{3}-\mathrm{CeO}_{2} \mathrm{NC}(\mathrm{A}), \mathrm{Ag}-\mathrm{CeO}_{2} \mathrm{NC}(\mathrm{B}), \mathrm{Ag}-\mathrm{CeO}_{2} @$ $\mathrm{TiO}_{2} \mathrm{NC}(\mathrm{C})$ and their cumulative $\mathrm{Ag}^{+}$release (D), (modified from refs [17] and [18])

rated $\mathrm{Ag}^{+}$to $\mathrm{AgNP}$ because $\mathrm{CeO}_{2}$ can be easily photosensitized.

As the release of $\mathrm{Ag}^{+}$is the key factor for antimicrobial activity it was quantified by inductively coupled plasma optical emission spectroscopy (ICP-OES) of supernatants taken from $\mathrm{AgNO}_{3}-\mathrm{CeO}_{2}$ immersed in water. A fast burst release within 5 days was followed by a 3 week period of slow release (see Fig. 2D). After ca. 4 weeks the cumulative $\mathrm{Ag}^{+}$release reached a plateau at about $85 \%$ of the total Ag content.

To prolong the $\mathrm{Ag}^{+}$release, $\mathrm{AgNO}_{3}$ was replaced with AgNP that were synthesized in presence of the PS template beads via reduction of $\mathrm{AgNO}_{3}$ with $\mathrm{H}_{2} \cdot{ }^{[17]}$ Coalescence, induced by sonication, embedded the AgNP in the PS spheres, following which these beads were coated with ceria. Calcination resulted in polydisperse Ag-PS@ $\mathrm{CeO}_{2} \mathrm{NC}(150 \mathrm{~nm}-2 \mu \mathrm{m})$ with a Ag content of $0.07 \mathrm{wt} \%$ and a ceria shell thickness of 15-20 nm (see Fig. 2B). A continuous release profile of $\mathrm{Ag}^{+}$in water with less than $30 \%$ of the total Ag content set free after three months makes this type of $\mathrm{NC}$ a promising candidate for long term infection prevention (Fig. 2D).

To further prolong the $\mathrm{Ag}^{+}$release, the $\mathrm{Ag}-\mathrm{CeO}_{2} \mathrm{NC}$ were subjected to an additional coating process with titania (Figs 1 and 2, C), resulting in Ag-CeO @ $\mathrm{TiO}_{2} \mathrm{NC}$ with a $30-60 \mathrm{~nm} \mathrm{TiO}$ layer. ${ }^{[18]}$ These $\mathrm{NC}$ could be subjected to a calcination step in order to transform the amorphous coating into a crystalline one (anatase). For pure $\mathrm{CeO}_{2} @ \mathrm{TiO}_{2} \mathrm{NC}$ this procedure increased the pore sizes of the material from 2-5 to 6-8 $\mathrm{nm}$. As the $\mathrm{Ag}^{+}$release is expected to be lower with small pores, a higher poten- tial for $\mathrm{Ag}^{+}$retention is attributed to amorphous $\mathrm{TiO}_{2}$ shells. Indeed, already after one day, the $\mathrm{Ag}^{2}$ ion release from amorphous $\mathrm{Ag}-\mathrm{CeO}_{2} @ \mathrm{TiO}_{2}$ in water stagnates after an initial burst corresponding to $7 \mathrm{wt} \%$ of the total Ag content (see Fig. 2D), which was attributed to small AgNP that migrated to the surface of the NC during synthesis. After three months of silver retention, the total remaining Ag of the samples was released by addition of concentrated nitric acid. This shows the potential for an ondemand, triggered release of $\mathrm{Ag}^{+}$ions from the containers only in presence of bacteria, as many microbial species tend to acidify their environment. [19]

The antimicrobial efficacy was verified for all NC by agar diffusion assays using $90 \mathrm{mg}$ pellets on $E$. coli cultures. They showed a clear antimicrobial effect by visible inhibitions zones around the pellets (Fig. 3). The extent of bacterial inhibition follows the trend of the materials to release $\mathrm{Ag}^{+}$. Due to the higher release from the $\mathrm{AgNO}_{3}-\mathrm{CeO}_{2} \mathrm{NC}$ their inhibition zone was larger ( $4 \mathrm{~mm}$ vs. $2 \mathrm{~mm}$ ) than for $\mathrm{Ag}-\mathrm{CeO}_{2}$. Despite the exceptional control over the $\mathrm{Ag}^{+}$ion release even for $\mathrm{Ag}-\mathrm{CeO}_{2} @ \mathrm{TiO}_{2}$ a small inhibition zone could be detected $(0.5 \mathrm{~mm})$.

As titania shells demonstrated such efficient control over the $\mathrm{Ag}^{+}$ion release the same synthetic approach was used to synthesize pure $\mathrm{TiO}_{2}$ NC.[16] The emulsion polymerization resulted in $190 \mathrm{~nm}$ PS spheres that were coated with $\mathrm{TiO}_{2}$ by hydrolysis and condensation of titanium isopropoxide similar to the synthetic route of Imhof (Fig. 1D). ${ }^{[13]}$ Several ways to remove the PS core were investigated. The dissolution of PS by liquid-solid extrac- 


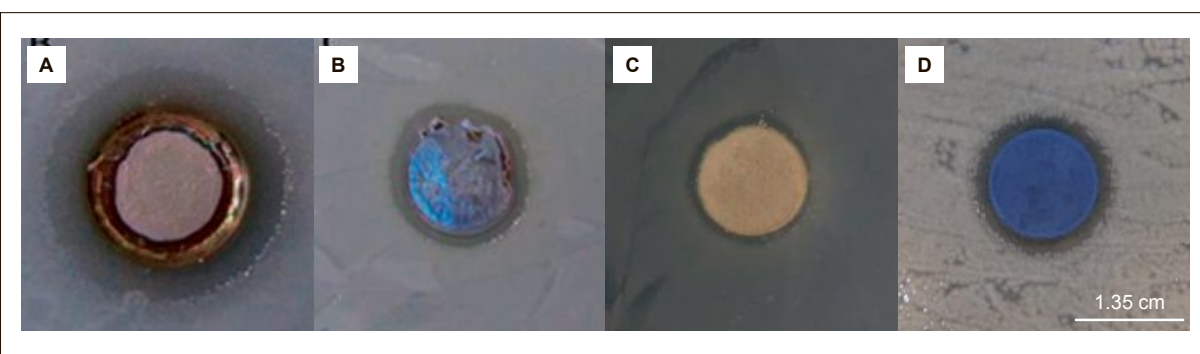

Fig. 3. Antimicrobial activity against $E$. coli by agar diffusion method: $\mathrm{AgNO}_{3}-\mathrm{CeO}_{2} \mathrm{NC}(\mathrm{A}), \mathrm{Ag}-\mathrm{CeO}$ $\mathrm{NC}(\mathrm{B}), \mathrm{Ag}-\mathrm{CeO}_{2} @ \mathrm{TiO}_{2} \mathrm{NC}(\mathrm{C})$, and $\mathrm{Ag}-\mathrm{TiO}_{2} \mathrm{NC}(\mathrm{D})$. (A, B and C modified from refs [17] and [18])

tion with a Soxhlet apparatus and chloroform as solvent was compared to calcination above $500{ }^{\circ} \mathrm{C}$ as used for the ceria NC. From $500{ }^{\circ} \mathrm{C}$ onward, the PS bands in the IR spectra vanish, while the bands of the O-Ti-O vibration of anatase (400$900 \mathrm{~nm})^{[20]}$ appear. In the case of the Soxhlet extraction of PS, residues remain after the extraction process and had to be removed by an additional calcination step. SEM images showed that if the PS core was removed before calcination the hollow structure could be preserved with intact walls up to a calcination temperature of $500{ }^{\circ} \mathrm{C}$ (Fig. 4B). If the core was not removed before thermal treatment, the $\mathrm{TiO}_{2}$ shells started to break from $300{ }^{\circ} \mathrm{C}$ on, as decomposing PS created holes in the shells (Fig. 4A), leaving only debris at $700{ }^{\circ} \mathrm{C}$. At ca. $700{ }^{\circ} \mathrm{C}$, destruction occurred regardless of the PS removal pathway and was attributed to ongoing growth of the $\mathrm{TiO}_{2}$ crystallites as well as the partial crystal phase transition to rutile.

AgNP were thus introduced into homogeneous anatase $\mathrm{TiO}_{2} \mathrm{NC}$ by preforming them on the PS spheres as for the $\mathrm{Ag}-\mathrm{CeO}_{2}$ NC (Fig. 1E), followed by $\mathrm{TiO}_{2}$ coating, Soxhlet extraction and calcination. The $\mathrm{Ag}-\mathrm{TiO}_{2} \mathrm{NC}$ preserved their monodisperse $200 \mathrm{~nm}$ diameter with a shell thickness of $20 \mathrm{~nm}$ and samples with $6.5 \mathrm{wt} \% \mathrm{Ag}$ showed an excellent antimicrobial activity against $E$. coli by inducing an inhibition zone of $1.8 \mathrm{~mm}$ (Fig. 3D). Gagnon et al. have shown a way to attach these types of NC to surfaces via sol-gel derived coatings. [21]

\section{Silica-etching Methods: Ag@SiO Nanorattles by Microemulsion and by Surface-protected Etching}

Besides the integration of small AgNP into the shells of NC, the nanorattle (NR) setup with a single, moveable core inside a hollow shell was investigated. Here, silica was used as preferred shell material as it easily forms tight silica coatings around preformed metal nanoparticles.[22] Two strategies were exploited to obtain Ag@ $\mathrm{SiO}_{2} \mathrm{NR}$ in two different size ranges. The first one is based on a reverse microemulsion synthesis that makes use of the dif- ferences in solubility of different silica precursors (Fig. 5A). ${ }^{[12]}$ The reverse microemulsion system is formed by cyclohexane, the surfactant Igepal-CO520 and water or aqueous $\mathrm{AgNO}_{3}$ solutions in the concentration ranges of $0.01-0.2 \mathrm{M}$. The size of the micelles controls the size of the final nanoparticles. Addition of hydrazine allows first the reduction of $\mathrm{Ag}^{+}$inside the water phase to AgNP, while subsequent addition of tetraethyl orthosilicate (TEOS) and (3-aminopropyl)trimethoxysilane (APTMS) results in the formation of silica shells around those AgNP. TEOS tends to be better soluble in the organic, i.e. cyclohexane phase, and APTMS, added as ethanolic solution, diffused into the aqueous phase inside the micelles. Thus a silica shell with a structural gradient is formed upon $\mathrm{NH}_{3}$-induced hydrolysis and condensation. The NR motive is obtained by an etching step of 40 min stirring in warm water $\left(60^{\circ} \mathrm{C}\right)$. The inner part of the silica surface protected etching. (A modified from ref. [12]). shell directly around the Ag core is hereby removed preferentially due to its less 'dense' or more 'porous' structure formed from APTMS with one non-hydrolyzable side chain. The resulting $25 \mathrm{~nm} \mathrm{Ag@} \mathrm{SiO}_{2}$ $\mathrm{NR}$ are presented in Fig. 5A. Depending on the $\mathrm{AgNO}_{3}$ concentration $(0.01,0.05$ and $0.1 \mathrm{M})$ the amount of filled silica containers can be tuned to Ag loadings of 3,13 and $23 \mathrm{wt} \%$, respectively, as determined by ICP-OES. Higher $\mathrm{AgNO}_{3}$ concentrations during the synthesis result in the formation of large AgNP, loss of the NR structure or even in the formation of uncoated AgNP.

In order to tune the size of the NR void which is limited in the microemulsion approach due to the small size of the micelles, another synthetic approach has been investigated. $\mathrm{Ag} @ \mathrm{SiO}_{2}$ core shell particles were transformed into NR by surface-protected etching. Among the countless different synthetic routes to AgNP the polyol process is one of the most studied ones. ${ }^{[23]} \mathrm{Ag}^{+}$ salts are hereby reduced at elevated temperatures in and by polyols (e.g. ethylene glycol) often in presence of surfactants or additional structure directing agents (e.g. polyvinylpyrrolidone, PVP). This process was used to synthesize $25 \mathrm{~nm}$ AgNP. [24] PVP as capping ligand is known to favor the heterogenic nucleation of silica on metal NP during a sol-gel synthesis over the homogeneous one that would result in pure silica spheres. ${ }^{[22,25]}$ A simple Stöber process ${ }^{[26]}$ could thus be used to obtain homogeneously coated $\mathrm{Ag} @ \mathrm{SiO}_{2}$ core shell

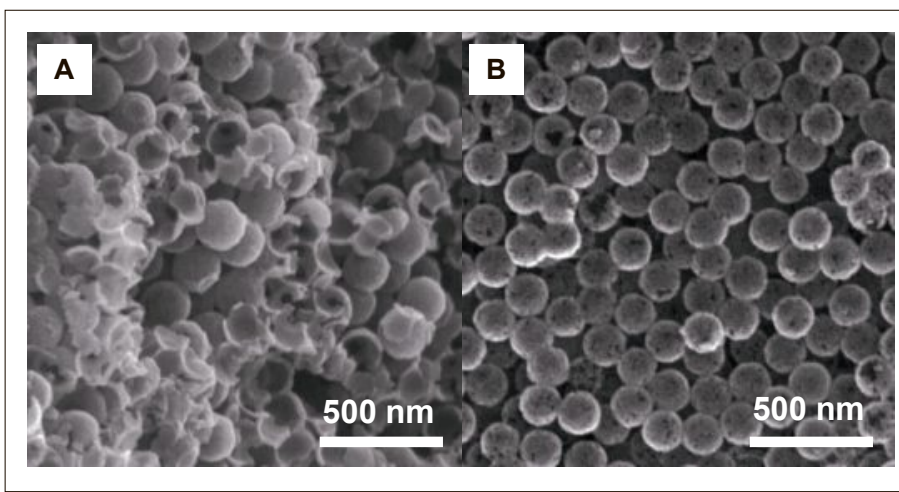

Fig. 4. Scanning electron micrographs of $\mathrm{TiO}_{2} \mathrm{NC}$ (calcination, A) and $\mathrm{TiO}_{2} \mathrm{NC}$ (dissolution + calcination, B) depicting the different level of shell preservation.

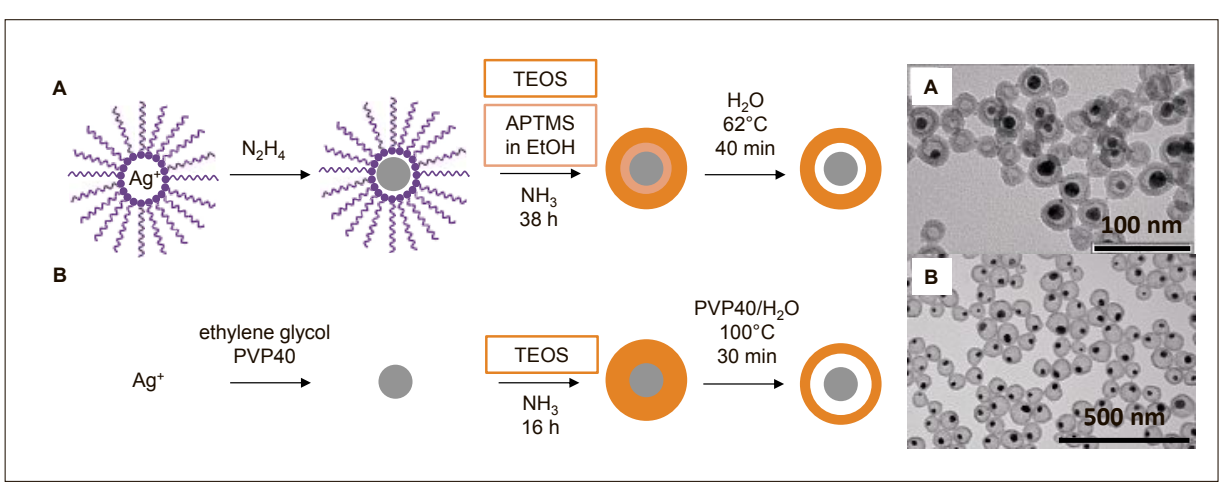

Fig. 5: Synthesis and transmission electron micrographs of ${\mathrm{Ag} @ \mathrm{SiO}_{2}}_{2} \mathrm{NR}$ by $\mathrm{A}$ ) microemulsion $\mathrm{B}$ ) 
particles from the polyol AgNP (Fig. 5B). In an additional etching step in presence of PVP, these core shell particles could be transformed into NR by selective removal of the inner part of the silica shell. ${ }^{[27]}$ PVP is indeed too large to diffuse through the pores of the silica, and hence protects the outer surface of the silica shells from etching. ${ }^{28]}$ The resulting NR were found in a size range of $80-115 \mathrm{~nm}$ in diameter, with a Ag content of about 20-24 wt\% (Fig. 5B) and a substantial amount of PVP bound in the system.

Both types of Ag@ $\mathrm{SiO}_{2} \mathrm{NR}$ have been evaluated for their antimicrobial efficacy by incubation of different pathogenic Gram-negative and Gram-positive strains in presence of different concentrations of the nanomaterials. ${ }^{[29]}$ The antimicrobial activity is strictly dose dependent in both cases. The surface-protected etching derived NR were compared to their precursor core shell particles. The results will be covered in a future publication. ${ }^{[30]}$ For the smaller, microemulsion-derived NR the Ag content determines the antimicrobial efficacy (Fig. 6). Moreover, an in-depth cytotoxicity evaluation of the smaller microemulsion-derived NR indicates a promising immunotoxicological profile. The in vitro experiments show particle uptake by dendritic immune cells in an active phagocytic process without affecting cell viability or inducing inflammation. These types of particles have also been proven to be useful in catalytic degradation studies. ${ }^{[12]}$

\section{Conclusion and Outlook}

A great variety of antimicrobial Ag@ oxide nanoparticles in terms of sizes and composition can be synthesized using three different methods. The choice of synthesis, material, shell thickness, template removal pathway or thermal treatment can all influence the properties, e.g. the antimicrobial activity. $\mathrm{Ag}-\mathrm{CeO}_{2}$ and $\mathrm{Ag}-\mathrm{TiO}_{2} \mathrm{NC}$ have shown a great potential for prolonging and controlling the $\mathrm{Ag}^{+}$release while demonstrating antimicrobial properties, a useful property for implant coatings. Selective dissolution of silica has been exploited for the synthesis of well-defined $\mathrm{Ag} @ \mathrm{SiO}_{2}$ $\mathrm{NR}$ in two size ranges with potential applicability in catalysis and antimicrobial coatings due to a surprisingly low cytotoxicity. These kinds of evaluations now allow the development of antimicrobial coatings that make use of the tuned $\mathrm{Ag}^{+}$release properties ensuring the biological tolerance of the particles.

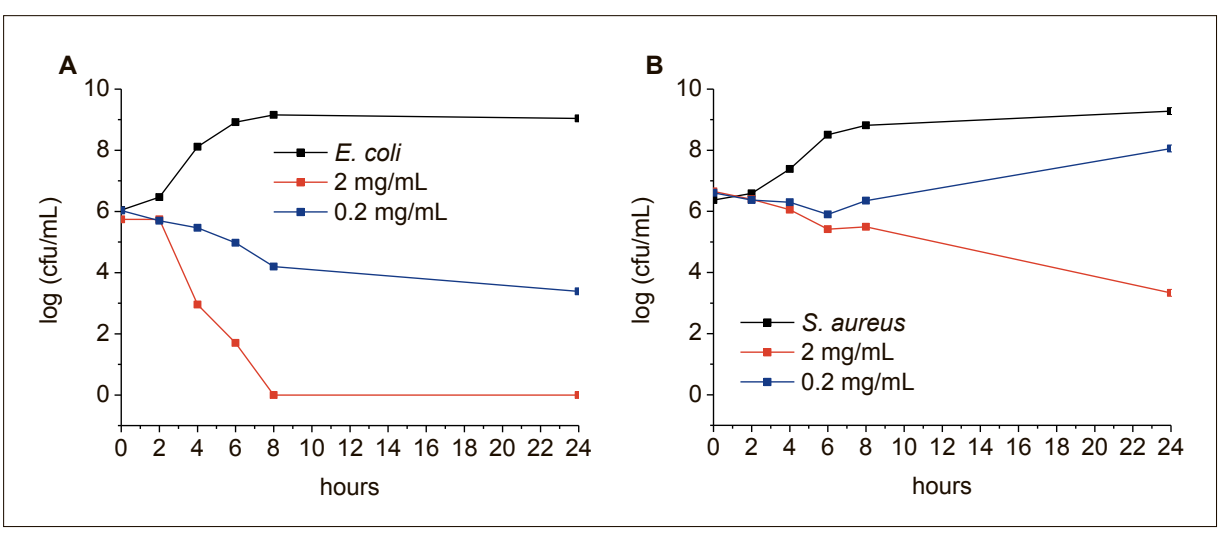

Fig. 6. Representative growth curves of $E$. coli $(A)$ and $S$. aureus $(B)$ in presence of the microemulsion derived ${\mathrm{Ag} @ \mathrm{SiO}_{2}}_{2} \mathrm{NR}$ containing 23wt\% Ag, (modified from ref. [29]).

\section{Acknowledgements}

The authors would like to thank the University of Fribourg and the Swiss National Science Foundation, in particular the National Center of Competence in Research "BioInspired Materials" for the generous funding of the project.

Received: January 22, 2018

[1] S. Eckhardt, P. S. Brunetto, J. Gagnon, M. Priebe, B. Giese, K. M. Fromm, Chem. Rev. 2013, 113, 4708.

[2] H. Zhang, M. Wu, A. Sen, in 'NanoAntimicrobials: Progress and Prospects', Eds. N. Cioffi, M. Rai, Springer Berlin Heidelberg, Berlin, Heidelberg, 2012, p. 3.

[3] R. M. Donlan, J. W. Costerton, Clin. Microbiol. Rev. 2002, 15, 167.

[4] H. J. Busscher, H. C. van der Mei, G. Subbiahdoss, P. C. Jutte, J. J. A. M. van den Dungen, S. A. J. Zaat, M. J. Schultz, D. W. Grainger, Sci. Transl. Med. 2012, 4, 153 rv10.

[5] a) T. V. Slenters, J. L. Sagué, P. S. Brunetto, S. Zuber, A. Fleury, L. Mirolo, A. Y. Robin, M. Meuwly, O. Gordon, R. Landmann, A. U. Daniels, K. M. Fromm, Materials 2010, 3, 3407; b) T. V. Slenters, I. Hauser-Gerspach, A. U. Daniels, K. M. Fromm, J. Mater. Chem. 2008, 18, 5359 .

[6] R. Kuehl, P. S. Brunetto, A. K. Woischnig, M. Varisco, Z. Rajacic, J. Vosbeck, L. Terracciano, K. M. Fromm, N. Khanna, Antimicrob. Agents Chemother. 2016, 60, 2467.

[7] M. Varisco, N. Khanna, P. S. Brunetto, K. M. Fromm, ChemMedChem 2014, 9, 1221.

[8] M. Priebe, K. M. Fromm, Chem. 2015, 21, 3854.

[9] J. Liu, S. Z. Qiao, J. S. Chen, X. W. Lou, X. Xing, G. Q. Lu, Chem. Commun. 2011, 47, 12578.

[10] X. Wang, J. Feng, Y. Bai, Q. Zhang, Y. Yin, Chem. Rev. 2016, 116, 10983.

[11] X. W. Lou, L. A. Archer, Z. Yang, Adv. Mater. 2008, 20, 3987.

[12] M. Priebe, K. M. Fromm, Particle \& Particle Sys. Charact. 2014, 31, 645.

[13] A. Imhof, Langmuir 2001, 17, 3579.

[14] A. F. Demirors, A. van Blaaderen, A. Imhof, Langmuir 2010, 26, 9297.
[15] A.-H. Pei, Z.-W. Shen, G.-S. Yang, Mater. Lett. 2007, 61, 2757.

[16] N. Hérault, K. M. Fromm, Helv. Chim. Acta 2017, 100, e1700014.

[17] J. Gagnon, M. J. D. Clift, D. Vanhecke, D. A. Kuhn, P. Weber, A. Petri-Fink, B. RothenRutishauser, K. M. Fromm, J. Mater. Chem. B 2015, 3, 1760 .

[18] J. Gagnon, M. J. D. Clift, D. Vanhecke, I. E. Widnersson, S. L. Abram, A. Petri-Fink, R. A. Caruso, B. Rothen-Rutishauser, K. M. Fromm, J. Mater. Chem. B 2016, 4, 1166.

[19] L. Zhang, F. Su, X. Kong, F. Lee, K. Day, W. Gao, M. E. Vecera, J. M. Sohr, S. Buizer, Y. Tian, D. R. Meldrum, RSC Adv. 2016, 6, 46134.

[20] N. Sharotri, D. Sud, Desalin. Water Treatm. 2016, 57,8776

[21] J. Gagnon, R. A. Caruso, K. M. Fromm, AIMS Bioengin. 2017, 4, 171 .

[22] C. Graf, D. L. J. Vossen, A. Imhof, A. van Blaaderen, Langmuir 2003, 19, 6693.

[23] M. Rycenga, C. M. Cobley, J. Zeng, W. Li, C. H. Moran, Q. Zhang, D. Qin, Y. Xia, Chem. Rev. 2011, 111, 3669

[24] P.-Y. Silvert, R. Herrera-Urbina, N. Duvauchelle, V. Vijayakrishnan, K. Tekaia Elhsissen, J. Mater. Chem. 1996, 6, 573.

[25] K. M. Koczkur, S. Mourdikoudis, L. Polavarapu, S. E. Skrabalak, Dalton Trans. 2015, 44, 17883.

[26] W. Stöber, A. Fink, E. Bohn, J. Colloid Interface Sci. 1968, 26, 62 .

[27] F. Hu, Y. Zhang, G. Chen, C. Li, Q. Wang, Small 2015, 11, 985 .

[28] Q. Zhang, T. Zhang, J. Ge, Y. Yin, Nano Lett. 2008, 8, 2867.

[29] M. Priebe, J. Widmer, N. Suhartha Lowa, S. L. Abram, I. Mottas, A. K. Woischnig, P. S. Brunetto, N. Khanna, C. Bourquin, K. M. Fromm, Nanomed.: Nanotechnol. Biol. Med. 2017, 13, 11.

[30] S. L. Abram, K. M. Fromm, manuscript in preparation, 2018. 